\title{
Pelas letras do vazio: as categorias de desaparecidos $e$ ausentes na Argentina dos anos 1970
}

\author{
The categories of missing and absent persons \\ in the Argentina of the 1970's
}

\section{Marina Maria de Lira Rocha}

Mesmo assim, os rostos dos parentes que procuravam o La Opinión, mais a convicção absurda de que era possível recuperar um ser humano, mais a necessidade de acreditar que um jornal se constitui numa instituição poderosa, impediam qualquer decisão que não a de publicar esses pedidos. De outra maneira, bastava dizer a essas pessoas para esquecer isso, aceitar a morte, que não se podia fazer nada, e que deviam rezar. Mas isso era o que a religião lhes dizia. Ou, então, dizer que tivessem paciência, mas isso era o que os políticos lhes diziam. Ou dizer que era melhor não criar escândalo, pois isso implicaria uma sentença de morte, mas isso era o que a polícia lhes dizia. Ou não recebê-los, o que era

\footnotetext{
Marina Maria de Lira Rocha é mestranda do Programa de Pós-Graduação em História Social da Universidade Federal Fluminense, Niterói, Brasil, orientada pelo professor Norberto Ferreras e bolsista da Capes (mmlrocha@hotmail.com).

Artigo recebido em 28 de junho de 2009 e aprovado para publicação em $1^{\circ}$ de setembro de 2009.
}

Est. Hist., Rio de faneiro, vol. 22, n. 44, p. 422-438, julho-dezembro de 2009. 
a política dos outros jornais. Assim, a única alternativa que restava era recebê-los, publicar o que tinha de ser publicado, informá-los que havia ocorrido casos de reaparecimento de pessoas e que deviam continuar lutando. Ou então fechar o jornal. (Timerman, 1982: 115-116)

Este artigo pretende analisar a constituição da categoria do "desaparecido" enquanto signo na Argentina, em um período no qual se encontra uma política peronista governante e desestabilizada, possibilitando uma maior disputa por poder materializada nas construções conceituais. Considerar-se-á esta categoria através das solicitadas, ${ }^{1}$ entre junho de 1975 e março de 1976, período que se encontra como forte indicador da crise política que se inicia no Rodrigazo e se estende até o golpe militar. Nesse período, ocorrem discussões sobre o desaparecimento, a partir de reclamações realizadas por organizações sociais e familiares dos desaparecidos, decorrente do processo de ampliação da repressão, desde o final da década de 1960, incluindo sua institucionalização.

$\mathrm{O}$ alargamento do sentido da violência foi acompanhado pela transformação, os adventos e as disputas por significância de outras categorias, como a de desaparecido, que intentavam dar explicações e influenciar a realidade vivida durante aquela década. Pretende-se expor, pois, as primeiras delineações do "desaparecimento" e percebê-lo inserido em uma discussão maior sobre a repressão, a "subversão" e o "terrorismo" para aquela sociedade, assim como sua concretização, sob uma perspectiva, nas redemocratizações e nos juízos contra repressores, no qual perde suas características e passa a ser designado hegemonicamente pelas contestações e visões dos organismos de direitos humanos.

As solicitadas, que aqui se analisam, são provenientes do jornal La Opinión, possuidor de uma maior possibilidade para visualização destes conteúdos, devido à quantidade destes comunicados. A especificidade de cada jornal na comercialização e maneira de divulgação das notícias é considerada neste trabalho como reflexo do entendimento quanto a seu posicionamento político a partir de suas ligações com as classes sociais. O jornal La Opinión, fundado pelo jornalista Jacobo Timerman, era uma publicação do início dos anos 1970, onde trabalharam os jornalistas Enrique Jara - preso-desaparecido junto com Timerman -, Enrique Raab - sequestrado em sua casa, interrogado na ESMA e ainda desaparecido -, Raul Vera Ocampo, Tomas Eloy Martinez-ambos do suplemento de cultura do jornal, tendo o último se autoexilado, em Caracas, entre 1975 e 1983 -, Edgardo Sajón - sequestrado no caminho para o trabalho no La Opinión, em 1977, e assassinado - entre outros nomes do jornalismo latino-americano e vítimas da repressão do Estado.

O público alvo deste diário era a classe média de Buenos Aires, La Plata e Córdoba, três cidades polos da intelectualidade argentina, com expressões universitárias, nas quais se assinalou um constante crescimento da politização da juven- 
tude. Direcionando-se para a negociação de notícias e de preocupações deste grupo social, diferentemente do argumento da citação de seu fundador acima colocada e marcada pela generosidade e distinção quanto aos demais jornais, o referido diário tinha de receber e publicar os casos de repressão desses indivíduos, na medida em que a violência ia fazendo parte da realidade da classe média, ${ }^{2}$ conformando aquele jornal como uma instituição, senão poderosa, ao menos interdependente deste grupo - falando de e para este interlocutor.

Neste sentido, trabalhar com aquilo que se produziu textualmente, remetendo-se a um interlocutor direto, como no caso dos leitores de um jornal lembramos aqui Bakhtin (1981), que afirma não haver discurso que não esteja socialmente encaminhado quanto à sua elaboração e recepção -, traz à tona os objetivos destes grupos em publicar suas ideologias e a necessidade de expandi-las para o convencimento.

Percebendo a enunciação própria de cada jornal, Eliseo Verón (2004) apresenta o conceito de contrato de leitura, estabelecido com a produção do discurso e a pré-concepção esperada do leitor deste, para explicar o fenômeno de reconhecimento do leitor no periódico e do periódico que cada leitor está disposto a interpretar. Assim, a publicação de solicitadas em jornais de circulação nacional identifica um interesse comunicativo de organizações em relação ao público deste periódico.

A fim de que a publicação faça sentido, se estabelece quem participa e consome determinadas produções sociais e quem, então, irá ter contato com a publicação. De tal modo, os "solicitantes" dos comunicados publicados não podiam definir precisamente quem os leria ou interpretaria de forma mais adequada, contudo podiam trabalhar com possibilidades.

Desmistificando a explicação do fundador do La Opinión, que afirmava a ausência de vantagens em publicar suas matérias valorando os direitos humanos (Timerman, 1982: 117-118), e percebendo que o jornal havia desde seu princípio se vinculado a um grupo social (Blaustein e Zubieta, 2006), verifica-se que essas temáticas se relacionavam com a concepção de mundo dos consumidores daquele discurso e, por conseguinte, com aquilo que se esperava ser lido pelo contrato de leitura. Construído desta forma, parece-nos claro o acoplamento de solicitadas sobre o desaparecimento destes indivíduos, enquanto constituintes de uma classe média que escreve a partir de sua posição social e dirige-se aos seus pares, a fim de buscar respostas e apoio, com maior probabilidade de conectar-se que em outros diários da época.

\section{A ação de desaparecer e o sujeito desaparecido}

O signo "desaparecido", no Cone Sul, implicou a existência do sujeito e sua ausência forçada, mesmo que fazer desaparecer tenha sido uma tentativa de escon- 
der o crime, ou seja, desaparecer com um nome. Ludmila Catela (2002: 45) afirma que esse termo, no Brasil e na Argentina, tem significados distintos: no primeiro país, é determinado por sua falta de notícias, enquanto, no segundo, o é por sua ausência. Parece-nos que a explicação para esta diferença está nos distintos meios de estabilização da repressão, e de luta contra ela, empregados nos dois países.

Isso significa que, no Brasil, os documentos produzidos pela ditadura trazem uma maior possibilidade de se reconstituir o paradeiro de indivíduos presos, sequestrados ou mortos pela repressão, que numérica e comparativamente constituem um menor grupo. Já na Argentina, por sua vez, com sua expressão clandestina de terrorismo de Estado, essa reconstituição é dificultada, tendo de ser realizada por testemunhos ou, quando corpos são encontrados, pela utilização da antropologia forense. $^{3}$ Além disso, a influência da luta política pelo aparecimento na Argentina e a pugna posterior por juízos contra repressores provavelmente influenciaram na ampliação deste signo, colocando sob ele grande parte de suas vítimas, sem caracterizá-las por crime: aqueles mortos, os presos cujos paradeiros se perderam, os sequestrados por organizações clandestinas ou oficiais, as crianças sequestradas etc.

Assim, é o desaparecido, enquanto grupo de pessoas ausentes, quem dá a marca e o impacto ao terrorismo de Estado argentino. Ele se apresenta como víti$\mathrm{ma} /$ prova dos crimes, nos quais existem executores específicos (os principais culpados, punidos pelo juízo) e cujas repercussões atingem a ideia de delitos contra a humanidade (Vezzetti, 2003: 18).

O desaparecimento, entretanto, pensado pelo viés conservador na década de 1970, poderia ser analisado como a finalização, o término, a eliminação do inimigo, em que os meios eram justificados pelos fins. Nesta discussão, acrescentam-se as ideias de violência positiva, enquanto explicada histórica e moralmente, e negativa, como destruidora dos valores sociais, que, antes de esvaziarem a ação política, ${ }^{4}$ foram instrumentos desta mesma ação, justificada e justificante.

Essa dialética fundamental, no caso do desaparecimento pensado como ausência ou como eliminação, segundo Bakhtin (1997), torna as palavras indicadoras de mudanças e constituintes materiais da exteriorização de ideologias no conjunto da vida social. Assim, o signo entra no domínio da ideologia, refletindo e refratando os seres que constituem a comunicação, possuindo contradições internas e, durante períodos de crise social ou comoção revolucionária, revelando-se como arena de disputas (Bakhtin, 1997: 45-47).

Percebemos, então, que os estudos, essencialmente, da ditadura, dos direitos humanos e de sua composição discursiva devem ser acompanhados pela trajetória específica deste conceito, como forma de estabelecer historicamente a refração social dos discursos que são pronunciados. Concebendo-o como não monolítico, nossa hipótese concentra-se na inclinação de que o termo "desapare- 
cido" foi uma formulação para afirmar a luta pelo aparecimento, pela finalização do "poder desaparecedor" e pela denúncia da ausência. Ele passa a existir, portanto, dentro de uma disputa contra a compreensão de desaparecimento/aniquilação do "terrorismo subversivo", buscada como hegemônica pela classe dominante. Desta forma, nega-se a identidade imposta aos desaparecidos, constrói-se um novo sentido para o próprio termo "terrorismo" e apontam-se as disputas ideológicas e as lutas reais concretizadas nele.

O estudo linguístico realizado por Lucrecia Chauvel (2002), por exemplo, indica a plurivalência do termo, quando o focaliza na imprensa argentina durante os anos de 1976 e 1983 . Assim, a autora coloca que entre os militares negava-se a desaparição com declarações cerimoniais que necessitavam de decifração pelos interlocutores (o general Camps declarou, em 1983, que "no desaparecieron personas sino subversivos"). Para o Estado, as afirmações de desaparecimento traziam a noção de atividade, confirmando os assassinatos, as deserções, a clandestinidade etc. "La labor más difícil es el hallazgo de personas que no han dejado huellas y no quieren ser encontradas" (La Nación, 02/05/1980). A imprensa, nessa composição, utilizava o termo para designar sujeitos. "No está ni muerta ni viva, frente a eso no podemos hacer nada" (La Nación, 17/12/79: 83), ou "El problema de los personas desaparecidas sea por la subversión, por la represión o por la determinación" (La Nación, 18/11/1978: 83), ou ainda "Terminar con el tema de los desaparecidos es terminar con el terrorismo" (La Nación, 23/02/1980: 84). As ações de familiares e das organizações de direitos humanos, por sua vez, emergiam com a noção de desaparecimento qualificada pelo adjetivo "forçado", a fim de afirmar o caráter vitimário e fixar o que a autora chama de "flutuações semânticas". A disputa pela definição dos desaparecidos e por sua identificação, portanto, principalmente durante a Guerra das Malvinas, passou a carregar uma postura individual das identidades sociais. ${ }^{5}$

Logo, Chauvel identifica, no período, uma longa disputa pela significância do "desaparecimento", que acabou por estabilizar-se como um termo social que, apesar de individual pela necessidade da identificação, designa a ausência generalizada. Neste sentido, verifica-se que a palavra, naquele momento, revela um caráter político, projetado na vida pública, de individualização e intensificação da proposta de antiviolência, descaracterizando a luta dos militantes desaparecidos e amenizando o significado de desaparecer tanto para os militantes quanto para aqueles que ansiavam o desaparecimento da "subversão". 6

Segundo Pilar Calveiro (2005: 15-17), a reconstituição histórica dos militantes desaparecidos, realizada a partir de perspectivas de valores atuais e individualização do mundo, pode refletir na perda de sentido do que se desejava ser: "Revolucionario, con una vida sacrificada, de renuncia de la plenitud personal para obtener un fin superior y colectivo. Esto es lo que a sus ojos resaltaría la in- 
justicia de su asesinato" (Calveiro, 2005: 16-17). A autora, confirmando e repensando sua experiência política pessoal, dá significado ao desaparecimento pela violência criada nas práticas vigentes durante a ditadura, que haveria se configurado como uma nova forma, o "poder desaparecedor". Deste modo, além de se desviar das explicações sobre um excesso de violência já praticada desde os anos 1930 no país, afirma o desaparecimento em via dupla: desaparecer por motivações de militância política e fazer desaparecer quem possuía estas motivações.

Recorrendo a Verón e Sigal (2004), que expõem a violência como produto de uma ordem simbólica, por representar um comportamento social e político, Marina Franco (2008) analisa os discursos com esta temática, entre 1973 e 1976, estabelecendo quatro conjuntos de abordagem pública: a recusa; a resultante de enfrentamento de dois extremos; a violência subversiva; e a violência como guerra. A autora coloca sua hipótese central na afirmação de que a sociedade condenava sistematicamente a violência, contrariando a perspectiva de que esse tipo de discurso era aceito e afirmando a responsabilidade social pelo golpe militar de 1976.

Sua análise parte de um princípio de violência cujo sentido seria igualitário para os muitos e diferentes grupos pesquisados, a fim de enquadrar os discursos em grupos temáticos de análise. Ao inserir a discussão na realidade objetiva da sociedade dos anos 1970, contudo, verificamos que a violência enquanto discurso não existe sem as bases da realidade de ação que se modificam na sua representação, quando em perspectivas ideológicas distintas. Logo, a condenação da violência pode ser entendida como condenação das propostas do outro, a fim de reafirmar os próprios espectros e justificar a violência praticada de seu ponto de vista.

\section{Os desaparecidos entre junho de 1975 e março de 1976}

O governo peronista de Isabel Perón, que se estendeu de julho de 1974 a março de 1976, foi marcado pelo aprofundamento do projeto de eliminação do elemento subversivo, que angariava a carga de sujeitos dissidentes do peronismo. ${ }^{7}$ Segundo Di Tella (1983: 125-127), o projeto de governo de Isabel possuía cinco objetivos gerais: suprimir a subversão com a ajuda das Forças Armadas e de grupos paramilitares; eliminar a esquerda na educação; acabar com as políticas antiempresariais do sindicalismo argentino, invocando a disciplina industrial dos trabalhadores, a fim de atrair capital estrangeiro e privado; e obter o apoio político das Forças Armadas. Institucionalizando a repressão, através da Lei Antissubversiva (setembro de 1974), da Declaração do Estado de Sítio (novembro de 1974), da reformulação da polícia (novembro de 1974 e setembro de 1975), da Decretação do Operativo Independencia (fevereiro de 1975), da formação 
dos primeiros Centros Clandestinos de Detenção, ${ }^{8}$ da criação do Consejo de Seguridad Interna (outubro de 1975), e da não restrição dos grupos paramilitares que se ocupavam em exterminar os "elementos apátridos", o governo peronista legalizou alguns métodos de repressão e estabeleceu essa retórica de desaparecimento no campo oficial.

No campo extraoficial, tem-se a ativação da violência pelos diversos grupos políticos, bastante analisados em diferentes estudos, e as contendas ideológicas entre eles, que eram, concomitantemente, constitutivas. Portanto, as ações e as respostas a elas, em graus desiguais, se compunham em uma totalidade política. Esta totalidade, por sua vez, nos traz uma possibilidade de entendimento do significado da violência nesse momento.

Enfocando os comunicados relacionados ao tratamento dos desaparecidos argentinos enquanto ausentes do convívio social, verificamos solicitadas que se referem a três tipos de conteúdos: sequestros, mortes e prisões ilegais de pessoas cujo aparecimento se reclamava. Mesmo havendo comunicados ideologicamente distintos referentes a sequestros, mortes e prisões, trabalhou-se aqui com a ideia de desaparecimento/ausência a partir daqueles indivíduos alheios que participavam da militância política fora da direita conservadora, pois eles foram os alvos da repressão militar e os formadores das posteriores listas de "desaparecidos", quando o termo já possuía uma significância consolidada. ${ }^{9}$

A categoria tornou-se mais difícil quando se trabalhou a ausência por morte, pois esta foi relatada com mais frequência em solicitadas de organizações desde as direitas às esquerdas políticas argentinas. Entretanto, persistimos em considerar a significância da nossa temática necessariamente desligada da interpretação vinculada a indivíduos das direitas, mesmo que sem ideologia definida ou promulgada.

Sob esta perspectiva, encontrou-se no período um total de 18 solicitadas. Elas foram assinadas principalmente por familiares dos ausentes, mas também pela Federación Juvenil Comunista, pelo Partido Comunista Revolucionario, pela Liga Argentina por los Derechos del Hombre, pela Asociación de Psicologos de Buenos Aires, e pela Franja Morada.

Apesar de não utilizar o termo "desaparecido", parece-nos que o sentido de ausência, fundacional da categoria, justifica a determinação do ausente/desaparecido, assim como a permanente presença da palavra "desaparecimento", o não saber onde se encontrarão tais pessoas, e a eliminação injusta, que estão em torno do conceito. De tal modo, esses desaparecidos eram indivíduos provenientes da atividade e não da passividade, que afirma o caráter vitimário, cuja construção foi sendo feita pelos organismos de direitos humanos.

Os direitos humanos na América Latina reformularam seus paradigmas, a partir de meados de 1970, ao incorporar nos debates sobre a marginalidade e as questões de classe, essenciais ao tema durante os anos 1960, os sentidos da 
repressão e do terrorismo de Estado e, consequentemente, a luta antiditatorial e contrária à violação dos direitos do homem. A movimentação das redes de familiares de vítimas, membros de comunidades religiosas, ativistas, organizações internacionais, alguns políticos e exilados foi decisiva para a quebra do padrão anterior e a ampliação de sua noção. Desenvolveu-se a violência em oposição à humanidade, colocando-se o Estado comprometido com a vigilância e com o cumprimento deles. Nos 1980, essa discussão desviou-se para a questão da democratização enquanto oposição à ditadura e para a necessidade de se erigir a cidadania política. Já nos anos 1990, quando se retoma com maior afinco a questão dos desaparecidos, é trazida uma postura de reconstrução da memória e da necessidade de justiça (Jelín, 2003).

A desaparição entre 1975-76 é denominada mais enfaticamente nos casos dos relatos de sequestros. As solicitadas assinadas por familiares de sequestrados, algumas publicadas em conjunto, reclamando no total 19 pessoas (entre elas três crianças), ${ }^{10}$ constituem-se em descrições com um grande número de informações sobre o momento do acontecido, sempre finalizando com um apelo à sociedade, aos dirigentes políticos, às autoridades eclesiásticas ou aos órgãos de direitos humanos nacionais e internacionais pelo aparecimento com vida das pessoas citadas.

O princípio do desaparecimento estaria na "detenção irregular", realizada por pessoal uniformizado ou civil. Ou as informações sobre os desaparecimentos eram obtidas informalmente, ou nada se sabia daqueles submergidos. Nota-se, então, a presença do signo do silêncio, que pode designar um silêncio oficial, mas também um silêncio da sociedade diante dos casos, uma vez que muitos recorriam à humanização do leitor para a obtenção de informações, e se colocavam diante da sociedade, mostrando os episódios ocorridos ("Queremos que nuestro hermano aparezca, que no se cubra esto con un manto de silencio"¿Donde está el Doctor Fages?, 07/01/1976: 10).

Estão postas as questões de forma e conteúdo. Enquanto forma, a construção textual dessas solicitadas é, quase sempre, possuidora de uma carga emocional e invocativa, finalizando com apontamentos de órgãos e pessoas importantes para a obtenção de informação sobre esses indivíduos. E o conteúdo designa o desaparecimento, sempre associado ao seu par contraditório e complementar, a aparição.

Recurrimos también a los legisladores, dirigentes políticos, autoridades eclesiásticas y a todos los argentinos de buena voluntad que presten su sentido humano para evitar la proliferación de estos hechos, que así como hoy nos lastiman a nosotros, mañana pueden descargar la tragedia sobre muchas otras familias argentinas, alejando definitivamente de este suelo la pacificación que todos deseamos. (“ $¿ D o ́ n d e$ están nuestros hijos?”, 29/11/1975: 10) 
Com as listas dos seqüestrados, os familiares buscavam respostas, mas retiravam certo grau político dos militantes, não os associando a movimentos específicos, seja por motivos lógicos de repressão e justificativa desta, seja por considerarem estas pessoas como fora da disputa pelo poder vigente, logo, "inocentes" da acusação de serem "subversivos". Isso não significa que haja uma amenização do significado desse desaparecimento, pois é inegável que o apelo estimula a crítica aos acontecimentos e desafia a repressão pela denúncia.

As solicitadas de organizações políticas têm construções diferentes. A juventude do Partido Comunista, por exemplo, em um comunicado, delata sequestros e assassinatos, apontando como vítimas membros dos comitês em Córdoba, Villa Constituición, Tucumán e La Plata, afirmando o caráter dos sequestrados citados como militantes comunistas, trabalhadores ligados a sindicatos e dirigentes estudantis. Entretanto, nem todos os reclamados, nesta solicitada, são citados nominalmente: os trabalhadores estão conformados pelo conjunto, enquanto os principais estudantes estão apontados. Este posicionamento pode nos dizer sobre a importância de se reclamar a aparição dos dirigentes do partido ou da célula, mas também nos informa sobre a ligação entre o público do jornal e este grupo social - a classe média estudantil - e, assim, aponta uma denúncia dirigida. Tampouco todos os nominados eram membros do PC - como o caso do advogado Montonero Roberto Quieto. ${ }^{11}$ Isso pode enfatizar a condenação do Partido em relação à ilegalidade dessas ações, além de posicioná-lo como alvo no processo mais amplo de repressão. Desta forma, a desaparição ganha um sentido político, no qual há uma "ola de las bandas fascistas que impunemente azotan al país y a sus hijos de diferentes ideas políticas y religiosas" ("Ante la grave emergencia opina la Juventud Comunista", 23/01/1976: 9).

O Partido Comunista, nesse momento, colocava-se a favor de uma aliança cívico-militar, a fim de restituir a ordem política e econômica do país e de dar uma saída democrática à crise. ${ }^{12}$ Neste sentido, por esta solicitada, sua juventude afirma sua posição política, criticando a passividade do governo em relação à situação; aloca-se vítima da repressão e, principalmente, constitui seus interlocutores políticos como fascistas, violentos e desrespeitosos das diferenças, portanto, não democráticos. O desaparecido ganha uma identidade específica, o Partido se coloca em uma luta pela aparição dos sequestrados, "independentemente de sua posição ideológica ou religiosa", e pede pela justiça aos assassinatos, condenando, assim, a violência tanto da esquerda quanto da direita.

As noções de ausência e aparição, que conduzem toda a linha de construção desse conjunto de pessoas ditas desaparecidas, também são aplicadas às prisões por motivações políticas consideradas sem causa e ilegais. ${ }^{13}$ Nessas solicitadas é presente o sentido da aparição junto à noção de liberdade, reclamada mesmo quando não se sabe o paradeiro do detido. 
Los familiares de Rodolfo Caran, Estela López, Paula Mahler e Margarita Todesca, estudiantes universitarios detenidos a disposición del Poder Ejecutivo sin causa ni proceso, se dirigen a las Autoridades Nacionales a los efectos de solicitar la libertad de sus hijos para honrar dignamente el próximo 9 de Julio. ("Libertad a estudiantes detenidos para el día de la Independencia”, 06/07/1975: 9)

Veem-se, no comunicado acima, os familiares que buscam seus filhos, presos "sem causa nem processo", e cujas liberdades reclamam para a comemoração do Dia da Independência do país. Destaca-se aqui a denúncia familiar como uma das principais fontes de quebra do silêncio em relação à repressão, e como uma vertente formuladora da noção dicotômica da ausência/desaparecimento, a partir da busca individual desses sujeitos detidos.

Outra perspectiva é colocada pelos comunicados de organizações políticas. A Liga Argentina por los Derechos del Hombre, primeira organização de direitos humanos no país, fundada em 1937 e ligada ao PC, publica, em julho de 1975, uma lista com dezenas de nomes, obtidos por informações recebidas de familiares, advogados e filiações no interior do país, agrupando-os por prisões e afirmando que totalizam mais de duas mil pessoas. Diz a Liga:

Nunca se conocieron oficialmente los nombres de los detenidos, donde están alojados y mediante que decreto se ordenó su detención. Por ello, la lista es muy incompleta y los lugares de detención pueden variar porque los traslados se suceden diariamente.

(...) Entre los detenidos hay dirigentes sindicales y trabajadores en general, abogados defensores de presos políticos, jueces, ex deputados, médicos, arquitectos, ingenieros, profesores, maestros, estudiantes y profesionales de distintas disciplinas. Hay mujeres con pequeños bebés en la cárcel de Villa Devoto y hay mujeres en Rawson, Resistencia, Sierra Chica, San Nicolás etc. Y hay una cantidad muy grande de jóvenes a lo largo y ancho del país que purgan con la cárcel sus opiniones o la defensa de sus ideales. La mayoría se ha pronunciado por la legalidad constitucional y contra el terrorismo. Paradójicamente, no se sabe de ningún miembro de las Tres A que se halle detenido. ("Lo que el pueblo espera ahora", 26/07/1975: 7)

Percebe-se, portanto, a constituição de um grupo heterogêneo, com militâncias distintas e casos de prisões com motivações também diferentes, que são 
englobados em uma mesma lista a fim de se denunciar suas prisões e pedir sua reaparição com vida. Esta formação, partida de uma organização de direitos humanos, é compreensível, não apenas pelo objetivo da publicação - obter informações e pressionar pelo aparecimento - como também pela resposta à percepção de conjunto da própria repressão que atingiu esses indivíduos e que os enquadrava como "inimigos" e "subversivos", senão iguais no "castigo merecido" ao menos iguais no sentido da prisão.

Os desaparecidos, em sua maioria, segundo a Liga, eram vítimas de um terrorismo contra o qual lutavam, e só poderiam ser entendidos quando constituídos por esta oposição. Logo, a realidade sobre a aparição pode ser entendida como derivação de uma realidade maior de contendas pela exposição do oponente político.

Verifica-se, por exemplo, na citação acima, a referência aos membros das Três A - grupo paramilitar clandestino -, identificados como os verdadeiros terroristas. Isto se dá justamente em um período posterior ao Rodrigazo - movimento dos trabalhadores contra o ministro da Economia, Celestino Rodrigo, suas políticas econômicas e o ministro do Bem-Estar Social, López Rega, figura central da $\mathrm{AAA}^{14}$-, no qual a discussão sobre a violência clandestina é efervescente e a consolidação de um inimigo público é essencial para a política, por ficar evidente a participação de membros do governo e do aparato policial nessa organização.

A título de comparação, apresenta-se outra solicitada publicada pelo grupo político de oposição, Franja Morada, ${ }^{15}$ que denuncia a detenção dos estudantes da Faculdade de Direito de Buenos Aires, Raul Martin e Jorge Hermide. Nesse comunicado, a agrupação nega a posição do ministro da Educação, Oscar Ivanissevich, que realizou diversas intervenções nas universidades na época, e que, segundo a organização, considerou a Unión Cívica Radical como membro da "subversão".

Neste sentido, a agrupação coloca, como expressão fundamental para a criação do "ser subversivo", a questão do "terrorismo", sem defini-lo, mas constatando que sua prática ou defesa nunca teriam sido realizadas pela Franja Morada. Nessa construção, os outros são "subversivos" e devem ser reprimidos, contudo não a UCR, que nunca renunciou "a luchar por la defensa de los intereses estudantiles" (“Presos por Radicales”, 13/06/1975: 6).

Percebe-se que a ocultação militante criada pelas solicitadas das famílias submerge, tomando esses indivíduos, cuja aparição se deseja, como pessoas ativas, conscientes da luta política, com a "essência verdadeira" conectada à ideologia das organizações. Além disso, o próprio veículo da publicação - materializado no jornal pelas solicitadas - agrega, ao seu caráter denunciante, os aspectos de disputas políticas e de convencimento da opinião pública, que, no caso do $L a$ Opinión, como já visto, estava conformada por jovens universitários, aqueles que compunham tanto a Juventude do PC como a Franja Morada. 
Outro caminho de análise dessas solicitadas sobre prisões irregulares é a percepção desses sujeitos a respeito da denúncia de restrição às atividades culturais e científicas, que, apesar de estarem diretamente ligadas ao discurso oficial de contenção do "elemento subversivo", ${ }^{16}$ no discurso de determinados grupos aparece ligada às questões de trabalho e democracia. Assim, a Asociación de Psicologos de Buenos Aires, por exemplo, grêmio dos profissionais de psicologia, denunciou em comunicado a invasão ao Centro de Docencia e Investigación de la Coordinadora de Trabajadores de Salud Mental e a prisão ilegal de 18 profissionais e docentes da pós-graduação desse centro.

Frente a este avasallamiento, que es uno más de los que vienen padeciendo los trabajadores de la salud, de la cultura y el arte, nuestras asociaciones han resuelto mantenerse en el camino de la movilización en defensa de los derechos democráticos y la cultura hoy en peligro.

Mantener y redoblar nuestras actividades es el mejor camino para hacer retroceder todo intento de atacar nuestra reconocida labor científica y gremial en defensa de la salud pública.

Hacemos un llamado a todas entidades científicas y culturales a sumar su voz de protesta frente a este atropello y a mantenerse unidas y alertas para responder a todo intento similar. ("En defensa de la cultura y la libertad", 02/12/1975: 18)

Deste modo, os psicólogos participantes desse grêmio, identificando-se amplamente como trabalhadores da saúde e da cultura do país, denunciam a repressão e a censura dessas atividades, que são também uma violência sofrida nos âmbitos individual e coletivo. Logo, esses ausentes seriam vítimas representantes desse tipo de violência, complementando as denúncias específicas sobre a censura no país.

Por fim, têm-se as solicitadas referentes aos ausentes que denunciam suas mortes. Foram publicadas no jornal, nesse período, comunicados sobre assassinatos de integrantes de partidos políticos ou estudantes universitários ligados a movimentos, cujos textos eram escritos como relatos dos acontecimentos e pedidos de investigação e castigo para os crimes.

O Partido Comunista Revolucionário, por exemplo, descreve o sequestro e a aparição do corpo da estudante de história ou filosofia Patricia Tossi (há duas solicitadas sobre o caso, uma a expõe como estudante de história, outra como de filosofia). ${ }^{17}$ Havendo ingressado na casa da mãe da estudante, e não a encontrando, pessoas vestidas de policiais entraram na residência de seu irmão, onde 
esta dormia. "Luego de violentar la puerta, secuestraran a la compañera. Su cadáver apareció acribillado a balazos en la proximidad de la ruta 2, en el bario $\mathrm{R}$. Rojas, en Florencio Varela" ("Patricia Tossi: Estudiante asesinada por comunista revolucionaria, patriota e antigolpista", 26/06/1975: 16).

Para o PCR, esses crimes que ocorriam com estudantes filiados ao partido eram movimentos golpistas advindos tanto do imperialismo russo quanto do ianque. Deve-se colocar que esse partido maoísta, nascido de um racha com o PC Argentino, passou a defender o governo de Maria Estela Perón por considerá-lo antiimperialista, antioligárquico, terceiro-mundista e burguês nacional. Assim, determinava que os assassinatos de seus militantes, vinculados a adjetivações como patriotas e antigolpistas, tinham caráter de golpe, defendendo o peronismo das acusações de desgoverno e de falta de posição quanto à violência clandestina.

Logo, essas organizações partidárias, ao declararem a morte das pessoas, enfatizavam a própria luta, como se aquele indivíduo personificasse as características do movimento por completo. Institucionalizavam as pessoas, que seriam mistificadas como representantes da organização, detentoras da verdade política e injustiçadas por sua morte. Entretanto, não é simplesmente pelo assassinato individual que se julga a injustiça, e sim pelo fato de que a luta daquele ausente era pelo "bem coletivo" ou o "interesse geral da nação" e, portanto, sua ausência deveria ser punida.

\section{Considerações finais}

Apresentou-se acima um pequeno panorama das expressões do termo desaparição, percebendo-o como uma categoria de disputa entre "poder desaparecer com alguém" e "estar ausente forçosamente". Na última expressão, tentou-se mostrar as lutas internas pela determinação desse desaparecido/ausente e verificou-se, como princípio do conceito, uma disposição da atividade, da política e da denúncia, sob três perspectivas de abordagem: o sequestro, a prisão e a morte. A partir das análises, verificou-se que a constituição dos fatos, nas solicitadas do período, determinava o desaparecimento como uma ação política, mesmo quando implícito nas invocações familiares pelo aparecimento dos sequestrados ou presos.

Trabalhou-se com a possibilidade de que esta categoria tenha se transformado em passividade, entendendo a vitimização dos desaparecidos nas reclamações à sociedade por justiça. Defendeu-se que a vitimização desses indivíduos está no contraponto ao "poder desaparecedor" que os considerou igualmente "subversivos" e, portanto, necessitando de contenção. Ao mesmo tempo, teve-se em conta que esta visão foi aprofundada a partir de um período cuja responsabilidade social pela repressão foi dispensada por sua afirmação para a justiça e pela condenação de repressores em altas instâncias. ${ }^{18}$ 
Associou-se, entretanto, esta visão à despolitização e amenização da ausência, principalmente quando apelada pelos organismos de direitos humanos, cujo objetivo era obter justiça e punição aos repressores, constituintes da ditadura, como forma de estabelecer a democracia no país. Em nossa concepção, falar de desaparecimento é também discorrer sobre coerção de sujeitos históricos, supressão de projetos políticos, convencimento de propostas para o futuro do país, além das ausências coletivas e individuais.

Os desaparecidos são constantemente analisados, nos estudos atuais e nas reconstituições do terrorismo de Estado, como uma ausência coletiva presente e como a presença na lembrança sistemática do ausente em sua individualização, exposta à sociedade em seu caráter de vítima juvenil. A amenização do conteúdo do desaparecimento, ao longo do tempo, ${ }^{19}$ mais que tornar esse agente passivo, descaracteriza as posições políticas distintas e esconde as divergências históricas do próprio termo. Assim, a categoria de desaparecimento, quando utilizada, necessita se desvincular dos eufemismos e se atrelar ao conteúdo histórico do tempo em que é empregada ou que descreve, e, portanto, sustentar seu caráter de significância plural e disputada.

Notas

1. Espaços nos jornais argentinos destinados à publicação de comunicados diversos, que, portanto, exprimem opiniões distintas de atores sociais sobre acontecimentos políticos ou econômicos.

2. Waldo Ansaldi (2002), citando as proporções de desaparecidos, relata que $30 \%$ eram trabalhadores e $30,6 \%$ pessoas da cultura estudantes, atores, artistas, professores e jornalistas . E afirma que não bastava matar as pessoas, era necessário extinguir as ideais ligadas à categoria de subversão.

3. Para estudos sobre a antropologia forense, ver Olmo (2002: 179-194).

4. Cf. o trabalho de Verón e Sigal (2004), cuja análise do funcionamento e do conteúdo dos discursos peronistas nas décadas de 1940 a 1970 levou-os à conclusão de que houve um momento de afirmação da violência, acompanhada pelo esvaziamento político dos discursos.

5. Miguel Bonasso (1985) caracterizou os jovens sacrificados pela ditadura a partir de dois eixos: os "desaparecidos", que eram os militantes, os que tiveram de abandonar a militância e os exilados; e os "chicos de la guerra", que eram os filhos do processo, desinformados e deformados pelo Terror, e que foram convocados para lutar nas Malvinas. Chauvel, por sua vez, afirma que o discurso do desaparecimento cresce principalmente a partir da guerra, não separando a juventude nesses conjuntos estruturais, mas demonstrando uma posição integrada entre o contexto da 
guerra e a luta pelo aparecimento. O mesmo ocorre com a proposta de Vezzetti, que coloca a referida guerra como ponto principal para a discussão do desaparecido. Discussão esta que culmina nos juízos, nas ideias de punição aos repressores e na afirmação do Nunca Mais.

6. A luta das Madres de la Plaza de Mayo, por exemplo, acrescenta o caráter militante à luta pelo aparecimento de seus filhos já na década de 1990, quando o país ingressa em uma forte política liberal, que é combatida, posteriormente, pela luta dos piqueteros, trazendo à tona novamente a possibilidade de transformação política e perspectivas ideológicas.

7. Afirma-se o caráter momentâneo dessa designação, pois, a partir de 1955, a Argentina passou a sofrer com uma sucessão de golpes fundamentados na eliminação de um "inimigo subversivo", que era representante de forças políticas diversas, dependendo da ocasião.

8. Foram os Centros Clandestinos de Detenção, disseminados durante a ditadura, que deram fundamento material à ideia de desaparecimento forçado.

9. Esta é uma das possibilidades de aprofundamento do trabalho, já que as categorias analisadas são vistas como objeto de disputa entre classes e intraclasses, como exposto acima.

10. Para crianças desaparecidas e restituídas, ver Quadrat (2003).

11. Para Montoneros, ver Gillespie (1998).

Referências bibliográficas

ANSALDI, Waldo. El silencio es salud: la dictadura contra la política. In: QUIROGA,
12. Nestas solicitadas, pode-se averiguar o caráter de apoio de determinados partidos de esquerda às justificativas utilizadas para a intervenção militar na sociedade.

13. Neste jornal, há solicitadas sobre prisões de indivíduos de outras nacio- nalidades, principalmente uruguaios, como o dirigente sindical Hugo Cores e o senador Enrique Erro, que demonstram operações regionais de repressão, mas que não serão analisadas especificamente neste artigo.

14. Para "Três A", ver Jansen (1986).

15. Agrupação política ligada à União Cívica Radical, formada por jovens universitários.

16. Como já exposto acima, o estudo de Ansaldi aborda esta perspectiva de supressão das ideias pela repressão, para além da aniquilação dos homens.

17. A estudante encontra-se na lista de pessoas assassinadas pela Triple A. Disponível em: <http://www.desaparecidos.org/arg/ victimas/listas/aaa.html $>$.

18. Não se pode considerar, contudo, graus igualitários nas responsabilidades pela repressão. Apenas afirma-se que se poderia conhecer os fatos e que o silêncio também foi consciente.

19. Seriam interessantes estudos comparativos sobre a temática, que relacionassem os governos peronista e ditatorial da década de 1970 com a redemocratização e as lutas atuais dos direitos humanos.

Hugo \& TCACH, César (orgs). Argentina

1976-2006: entre la sombra de la dictadura y el 
futuro de la democracia. Rosario: Homo Sapiens, 2006.

BAKHTIN, Mikhail. Marxismo e filosofia da linguagem. São Paulo: Hucitec, 1981.

BONASSO, Miguel. De los "desaparecidos" a los "chicos de la guerra". Revista Nueva Sociedad, México, n. 76, 1985, p. 52-61.

CALVEIRO, Pilar. Política y/o violência. Una aproximación a la guerrilla de los años 70. Buenos Aires: Norma, 2005.

CATELA, Ludmila da Silva. Territórios de memória política. Los archivos de la represión en Brasil. In: CATELA, Ludmila da Silva \& JELIN, Elisabeth (comps.). Los archivos de la represión: documentos, memoria y verdad. Madrid: Siglo XXI, 2002, p. 15-84.

CHAUVEL, Lucrecia Escudero. Desaparecidos, pasiones e identidades discursivas en la prensa argentina (1976- 1983). Revista Galaxia, São Paulo, n. 3, vol. 2, 2002, p. 73-92.

DI TELLA, Guido. Perón-Perón (19731976). Buenos Aires: Sudamericana, 1983.

FRANCO, Marina. Notas para una historia de la violencia en la Argentina: una mirada desde los discursos del periodo 1973-1976. Disponível em: <http://nuevomundo.revues. org/index43062.html>, 2008.

GILLESPIE, Richard. Soldados de Perón. Los Montoneros. Buenos Aires: Grijalbo S.A., 1998.

GRIMSON, Alejandro \& VARELA, Mirta. Culturas populares, recepción y política. Genealogías de los estudios de comunicación y cultura en la Argentina. Disponível em: < htpp:// sala.clacso.org. ar $>$.

JANZEN, Ignacio Gonzáles. La Triple $A$. Tucumán: Contrapunto, 1986.
JELIN, Elizabeth. Los derechos humanos y la memoria. Cuadernos IDES, Buenos Aires, 2003, n. 2.

La Opinión. Junho de 1975 a março de 1976. Exemplares encontrados na Biblioteca Nacional de Buenos Aires.

MORANDINI, Norma. La oscuridad como marca. In: QUIROGA, Hugo \& TCACH, César (orgs). Argentina 1976-2006: entre la sombra de la dictadura y el futuro de la democracia. Rosario: Homo Sapiens, 2006.

OLMO, Darío. Reconstruir desde restos y fragmentos. El uso de archivos policiales en la antropología forense en Argentina. In: CATELA, Ludmila da Silva \& JELIN, Elisabeth (comps.). Los archivos de la represión: documentos, memoria y verdad. Madrid: Siglo XXI, 2002, p. 179-194.

QUADRAT, Samantha Viz. O direito à identidade: a restituição de crianças apropriadas nos porões das ditaduras militares do Cone Sul. Revista de História, São Paulo, n. 22, 2003, p. 167-181.

SIGAL, Silvia \& VERON, Eliseo. Perón o muerte: los fundamentos discursivos del fenómeno peronista. Buenos Aires: Eudeba, 2004.

TIMERMAN, Jacobo. Un desaparecido vuelve a casa. Revista Nueva Sociedade, México, n. 100, 1989, p. 204-215.

Prisioneiro sem nome, cela sem número. Rio de Janeiro: Codecri, 1982.

VERÓN, Eliseo. Fragmentos de un tejido. Buenos Aires: Gedisa, 2004.

VEZZETTI, Hugo. Pasado y presente. Guerra, dictadura y sociedad en la Argentina. Buenos Aires: Siglo XXI, 2002. 


\section{Resumo}

Este trabalho visa a analisar as categorias de desaparecidos e ausentes, na Argentina, durante os anos de 1975 e 1976, que se materializam em comunicados da época. Procura identificar a formação dos sentidos desses signos e as disputas por sua homogeneização, antes de sua consolidação sob a perspectiva dos organismos de direitos humanos. Fundamenta-se em marcos da teoria bakhtiniana da linguagem e na idéia de ação comunicativa em periódicos elaborada por Eliseo Verón. Busca entender a ligação desses termos entre o público e a publicação, assim como demonstrar a procura por convencer leitores através dessas categorias, dentro de perspectivas ideológicas.

Palavras-chave: desaparecidos, solicitadas, peronismo, jornais, Argentina

\section{Abstract}

This paper aims to analyze the categories of missing and absent persons in Argentina, during the years 1975 and 1976, as they appear in the solicitadas published in the press of the period. It tries to identify the meanings of these signs and the disputes on their homogenization before its consolidation in the perspective of human rights. It is based on the bakhtinian theory of language and on the idea of communicative action in newspapers conceived by Eliseo Verón. It tries to understand the connection between these terms, as well as to demonstrate the search for convincing readers through these categories within ideological perspectives.

Key words: missing persons, solicitadas, peronism, newspapers, Argentina

\section{Résumé}

Ce travail vise à analyser les catégories des disparus et absents en Argentine pendant les années 1975 et 1976, telles qu'elles se matérialisent dans les solicitadas publiées dans la presse de l'époque. Il cherche à identifier la formation des sens de ces signes et les disputes pour leur homogénéisation avant leur consolidation dans la perspective des organismes des droits de l'homme. Il s'appuie sur la théorie du langage de Bakhtine et sur l'idée d'action communicative des journaux elaborée par Eliseo Verón. Il cherche à comprendre le lien entre ces termes et à demontrer l'effort pour convaincre des lecteurs par le biais de ces catégories, dans des perspectives idéologiques. Mots-clés: disparus, solicitadas, péronisme, journaux, Argentine 